\title{
Nurses' attitude towards patient violence in emergency department
}

\section{Introduction}

A safe and therapeutic environment in all health care institutions is imperative for healthcare workers to deliver high quality care for people with different health needs. Unfortunately, patients' aggression and/or violent behaviors' towards health care workers are common phenomena in various clinical settings. These phenomena are not only limited to psychiatric care institutions/units but also extended to general care settings such as hospitals. ${ }^{1}$ While workplace violence can occur between various disciplines, patient violence towards nurses represents the most common form in the health care institutions. ${ }^{2,3}$

An Emergency department (ED) is a major gateway to health care for a large proportion of the general population. ${ }^{4}$ It is identified as one of the most high-risk areas for patient violence. ${ }^{5}$ Indeed, the prevalence of patient violence in EDs has risen to an alarming figure worldwide. Around $25 \%$ of the nurse respondent's experienced physical assaults more than 20 times in the 3 years preceding Gacki-Smith and his colleagues' study, ${ }^{6}$ and almost one-fifth of them experienced frequent verbal abuse.

\section{Impact of workplace in health care setting}

The short-term and longer-term impacts of patient violence are both substantial at both individual and organizational level. At the individual level, violence leads to both physical and psychological trauma, including frustration and anger. ${ }^{7}$ Staff may become afraid of patients and their job performance may be affected after an incident of patient violence. ${ }^{8}$ At the organizational level, patient violence is associated with lower quality of care provided for their patients. ${ }^{9}$ It also produces significant longer-term effects on recruitment and retention of nurses. ${ }^{10}$

\section{Contributing factors of violence}

There are many factors involved in the presentation of patient violence in EDs. From the theoretical perspective, it can be the result of patients' genetic abnormalities, unresolved personal conflicts, and a response to frustration at perceived unmet needs. ${ }^{11,12}$ However, none of these theories can fully explain the complexity of patient violence in the ED. It also assumes patients are largely responsible for their violent behaviors and fails to consider other contextual factors. Indeed, there is a growing recognition on understanding the causes of patient violence from multiple angles are broadly classified into patient-related; environment-related and interaction-related factors, which include staff morale, patient/staff ratio and ward policy and staff variables such as their educational level and years of clinical experience. ${ }^{13}$

\section{Nurses' attitude towards violence}

With more understanding of these risk factors, the frontline nurses may feel much safer and more confident in management of patient aggression, as well as in establishing therapeutic nursepatient communication and relationships. ${ }^{14}$ However, as suggested
Volume I Issue 3 - 2016

\author{
Wong Wai Kit \\ Department of Nursing, Hong Kong Polytechnic University, \\ Hong Kong
}

Correspondence: Wong Wai kit, Department of Nursing, Hong Kong Polytechnic University, Hong Kong, Email wai.kit.wong@polyu.edu.hk

Received: September 29, 2016 | Published: November 25, 2016

by many nurse researchers that nurses' attitudes towards causes and management of patient violence have a far-reaching impact, which can largely vary across patient populations and clinical settings. Therefore, the nurses' perception towards patient aggression and its correlated factors are worthwhile to study because nurse is a decision maker of how to improve their patient care and prevent any harms or injury on both staff and patients. ${ }^{15,16}$ Besides, nurses' attitudes can be mutually transferred to colleagues through communication and forming a culture in wards. The future managing style of nursing students after graduation also may be affected through professional socialization, ${ }^{17}$ which is the process by which individuals acquire the values, attitudes, morals, knowledge and skills owned by the group. ${ }^{18}$ Thus, it is important to obtain present nurses' attitude regarding patient violence and take measures to avoid cultivating a negative attitude among 'future' nurses. ${ }^{19-21}$

\section{Acknowledgements}

None.

\section{Conflict of interest}

The author declares no conflict of interest.

\section{References}

1. Wells $\mathrm{J}$, Bowers L. How prevalent is violence towards nurses working in general hospitals in the UK. Journal of Advanced Nursing. 2011;39(3):230-240.

2. Hegney D, Eley R, Plank A, et al. Workplace violence in Queensland, Australia: The results of a comparative study. International Journal of Nursing Practice. 2006;12(4):220-231.

3. Lin YH, Liu HE. The impact of workplace violence on nurses in South Taiwan. International Journal of Nursing Studies. 2005;42(7):773-778.

4. Rintoul Y, Wynaden D, McGowan S. Managing aggression in the emergency department: Promoting an interdisciplinary approach. International Emergency Nursing. 2009;17(2):12-127.

5. Kwok RPW, Law YK, Li KE, et al. Prevalence of workplace violence against nurses in Hong Kong. Hong Kong Medical Journal. 2006;12(1):6-9. 
6. Gacki Smith J, Juarez AM, Boyett L, et al. Violence against nurses working in US emergency departments. The Journal of Nursing Administration. 2009;39(7/8):340-349.

7. Hislop E, Melby V. The lived experience of violence in accident and emergency. Accident \& Emergency Nursing. 2003;11(1):5-11.

8. Fernandes CM, Bouthillete F, Raboud JM, et al. Violence in the emergency department: a survey of health care workers. CMAJ. 1999;161(10):1245-1248.

9. Arnetz JE, Arnetz BB. Violence towards health care staff and possible effects on the quality of patient care. Social Science and Medicine. 2001;52(3):417-427.

10. Jackson D, Clare J, Mannix J. Would want to be a nurse? Violence in the workplace- a factor in recruitment and retention. Journal of Nursing Management. 2002;10(1):13-20.

11. Ferns T. Considering theories of aggression in an emergency department context. Accident and Emergency Nursing. 2007;15(4):193-200.

12. Linsley P. Violence and aggression in the workplace: A practical guide for all healthcare staff. CRC Press; 2006. 140 p.

13. Laura I, Ferrari C, Large M, et al. Prevalence and risk factorsof violence by psychiatric acute inpatients: a systematic review and meta-analysis. PloS One. 2015;10(6):e0128536.
14. Martin T, Daffern M. Clinician perception of personal safety and confidence to manage inpatient aggression in a forensic psychiatric setting. Journal of Psychiatric and Mental Health Nursing. 2006;13(1):90-99.

15. Duxbury J, Hahn S, Needham I, et al. The management of aggression and violence attitude scale (MAVAS): A cross-national comparative study. Journal of Advanced Nursing. 2008;62(5):596-606.

16. Happell B, Harrow A. Nurses' attitudes to the use of seclusion: A review of the literature. International Journal of Mental Health Nursing. 2010;19(3):162-168

17. Lipscomb M, Ishmael A. Humanistic educational theory and the socialization of preregistration mental health nursing students. International Journal of Mental Health Nursing. 2009;18(3):173-178.

18. Pope T. How person-centred care can improve nurses' attitudes to hospitalized older patients. Nursing Older People. 2012;24(1):32-36.

19. Jansen GJ, Middel B, Dassen WN. An international comparative study on the reliability and validity of the attitudes towards aggression scale. International Journal of Nursing Studies. 2005;42(4):467-477.

20. Kansagra SM, Rao SR, Sullivan AF, et al. A survey of workplace violence across 65 U.S. emergency departments. Academic Emergency Medicine. 2008;15(12):1268-1274

21. McLafferty I. Attitudes towards hospitalized older adults. Journal of Advanced Nursing. 2004;47(4):446-453. 